having returned, the inhaler was again applied to the face and a little more chloroform sprinkled on from the drop bottle. The patient now suddenly became intensely rigid, the face blue and respiration arrested, but the pulse in the carotid, which had been observed throughout, continued to be perceptible for a few beats. The operation was at once stopped, the patient's head and shoulders were brought over the end of the operating table, and artificial respiration was commenced at once by Silvester's method. As there was no improvement tracheotomy was performed without delay, and inflation through the tube attempted. In the meantime two syringefuls of ether were administered hypodermically and an enema of brandy and beef-tea was given. As a last resource acupuncture of the heart was resorted to. Artificial respiration was continued throughout from the first bad sign and until the patient had been dead three-quarters of an hour, but all efforts failed to restore animation.

Necropsy.-CThis was made on Dec. 21st by Dr. Higgs and Mr. Messiter. On opening the body the Iungs, liver, spleen and kidneys were found engorged with blood and the venæcevæ and right heart distended; the left ventricle was firmly contracted and empty; there was no fluid in the pleuræ or pericardium; no valvular lesion of the heart; the wall of the right ventricle appeared rather thinner than normal; the brain was congested; there was no visible organic disease in any of the internal organs. The cause of deatb in this case was chloroform asphyxia. Exactly one ounce of the anæsthetic had been used.

Dudley.

\section{GLYCERINE IN CONSTIPATION.}

BY JAMES D. STAPLE, M.R.C.S. FNG., L.S.A. LoND., LATE HOUSE SURGEON AND VISITING SURGEON TO THE STOCK PORT INFIRMARY \&C.

DURING my residence at the Stockport Infirmary I gave glycerine enemata in over a hundred cases, and on referring to $\mathrm{my}$ notes I find that the quantity injected was one drachm for children and two drachms for adults, the syringe used being the special one sold by instrument makers for the injection of glycerine. The bowels acted generally within fifteen minutes, in some rare cases half an hour elapsed, and on two occasions the injections had to be repeated. Since then I have discontinued the enemata and now I administer the drug by means of a suppository or "glycone," which can be nbtained from any chemist at a small cost. The suppositories vary in strength, I believe, but some contain about 95 per cent. of glycerine; and the results are the same as when the glycerine is given by enemata. These little suppositories can be most easily and quite painlessly introduced and the patients can themselves insert them. If one suppository fails to act in from five to twenty minutes, which is a rare occurrence, the introduction of a second will soon have the desired effect. Some of the advantages of glycerine administered by this method are absence of pain, ease of administration, rapidity of action and absence of griping. Glycerine suppositories are particularly useful in cases where an aperient by the mouth is not advisable. In midwifery practice, too, they are very useful for rapidly emptying the bowels. In the chronic obstruction of old people, caused by hardened fæces in the lower bowel, glycerine suppositories are especially useful.

City-road, Bristol.

\section{HEREDITARY LUXABILITY OF ELBOW-JOINT.}

\section{BY P. A. KELLY, L.R.C.S.IREL}

THE surgeon is sometimes reminded that heredity may and does play an important part in surgery as in medicine. A case illustrative of this fact came under my notice last month. One evening in the early part of December a gentleman was exercising on a horizontal bar, from which be fell upon the palmar surface of the right hand. The right ulna was dislocated backwards and outwards at the elbow-joint. Under chloroform, with a little manipulation, this was reduced. A few days after, in conversation, he said : "I have always expected to have my elbow dislocated." I was surprised at this remark, and on questioning him learned the following curious history: When his father, now an old man, was a lad, he dislocated the right elbow-joint. The year following he sustained a like injury to the left. These dislocations were not reduced and after some time he complained of numbness in both hands. This feeling was accentuated in the Jittle finger and on half the ring fingers of both hands, The muscles began to waste. Clearly the ulnar and musculn. spiral nerves were implicated. The forearms became nere skeletons. He sought advice in London, but the injury was of too long standing for any good to be expected by treatment. He is still living and has some limited movement but the injured parts are very susceptible to cold. So much for the father. Twenty years ago one of his sons dislocated the left elbow. At the time the injury was diagnosed and treated as a fracture, but after a few months the bone was forcibly pulled into place. A certain amount of deformity remsined. Eight years ago another son also suffered a luxation of the same joint. This case, like the former one, was treated as a fracture. At one of the hospitals in Vienna this dislocation was reduced, with a fairly good result. The third son (my patient) has now regained the entire use of the joint. Barry, Cardiff.

\section{A FATAL CASE OF VOMITING OF PREGNANCY.} By James Oliver, M.D., F.R.S. Edin., F.L.S.

A Patient was sent to me at the Hospital for Women, Sohosquare, on Jan. 18th, 1893, by Mr. Melville of Caledonianroad. She was twenty-nine years of age and, although marriec seven years, had never before been pregnant. Menstruation, established at the age of fourteen, had recurred regularly every three weeks until Sept. 25th, 1892, since which date-i.e. for nearly four months-there had been complete amenorlivea. From the end of October until the week before Christmas she complained constantly of a feeling of sickness, but only occasionally during this period was there actual voniting. Since the week before Christmas she had vomited almost incessantly. If even the smallest quantity of fluid was taken it was ejected immediately. For one week she had complained of tenderness of the abdomen. Physical sions: The anterior abdominal wall was flat and so retracted that the anterior superior spines of the iliac bones stood out prominently. The abdomen was so extremely tender that the results of palpation and percussion could not be ascertained. Vaginal examination: The vagina was exceedingly tender, and there was noted a marked bulging of the anterior wall of this canal. The cervix was situated far back towards the sacrum and was closely applied to the left wall of the pelvis. It was surrounded by what appeared to be an œdematous collar of mucous membrane at the raginal roof. The cervix was not soft. The os looked downwards. On the right side the vaginal roof was pushed down below the level of the external os by a larue globular and cystis swelling. Bimanual examination : The abdomen was occupied by an oroid swelling which reached to about two inches abors the pubes and the greater diameter of which extended transversely. Palpation of this abdominal swelling could be equally perceived in both the swelling in the right fornix and the cervix. Both breasts were enlarged and tender, but no colostrum could be obtained. The pulse numbered 120 per minute and the temperature was normal. The temperature continued normal until the day before death, when it fell to $96^{\circ} \mathrm{F}$, but the pulse gradually increased in frequency. Death occurred on Jan. 30th, but for three or four days previonsly the patient had occasionally prolonged attacks of syncope.

Necropsy. - Here and there the skin of the face, chest and legs was of a deep lemon colour. On opening the abdomina? cavity the peritoneal sac was dry and there was no eridence of peritonitis. The uterus occupied more especially the rioht half of the pelvis and the fundus reached to about three inches above the pubes. Two small fibroid nodules each of about the size of a pea were observed in the anterior wall of the uterus close to the fundus. There was no evidence of tension in the broad ligaments and both ovaries and both tubes were apparently healthy. The uterus was removed intact. The bag of raembranes was then observed projecting beyond the external os. The posterior wall of the uterus had evidently yielded more to the pressure of the dereloping ovum than the anterior, for not only did it bulge more than the latter, but it was actually much longer and much thinner. The placenta was found detached, yet no hæmorrhage had resulted from the separation. It was a four months' foetus. The liver was of a pale-yellow colour ; it was soft and fatty but not enlarged. The gall-bladder, which was distended, contained bile of a deep olive-green colour. The spleen was rather small. All the other organs of the body were apparently healthy.

Gordon-square, W.c. 


\section{A NEW METHOD OF MANIPULATION FOR THE REPLACEMENT OF THE LOWER JAW WHEN DISLOCATED.}

BF Felix Roth, M.R.C.S., L.R.C.P.

$\mathrm{THE}$ patient is seated in an ordinary cane-bottomed chair ; he operator stands before him with one foot placed slightly to the right side and the other just in front of the patient and in the middle line. The operator is thus on a firm basis, with ihe legs well apart and fully extended. He then flexes himself at the hips and asks the patient to lean forwards and to place his forehead in the middle of the sternum of the operator's chest (but this position varies with the size of the patient's head). The operator now flexes his head so that iis chin grips the patient's head about the upper part of the occipital bone; he thus acquires a firm hold and has the head well under control between his chin and chest. The thumbs, protected in the usual manner, are placed in the patient's mouth and the fingers of both hands grasp the lower jaw. In this position reduction is facilitated, and the advantages over the ordinary methods are as follows: (1) The operator has the head under perfect control and perfectly fixed; (2) the line of force exerted by the operator's hands acts in the same line as the resisting force exerted by the operator's chin; (3) the operator's elbows being well flexed, he can exert a greater power by the force acting through the thumbs being close to the shoulders, and it will be found that he has greater power of muscular action in the terminal phalanges of the same; (4) the patient's head is also in a better position for replacing a dislocated jaw; (5) the operator needs no assistant and does not inconvenience inis patient by the excessive pushing and pulling about of the head during the reduction.

George-street, Portman-square, W.

\section{"LCERATIVE TUBERCULOUS AFFECTION OF THE LOBE OF THE LEFT FAR,}

WITH ANESTHESYA OF THE SAME SIDE OF THE FACE, COMPLICATED WITH SCABIES.

By W. Gilmore Eliss, M. D. BRUX., M.R.C.S., L.S.A., MEDICAL SUPERINTENDENT, GOVERNMENT LUNATIC ASYLUM, SINGAPORE.

A Porruguese Eurasian lad aged twelve, fairly well dereloped, mulatto coloured, hitherto healthy, was brought to me on Dec. 16th, 1892, suffering from ulceration of the lobe of the left ear, the affected part itching considerably. The lobe was swollen, livid and nodulated, ulcerated in places, and discharged a sanious fluid of a peculiarly disagreeable odour. The patient stated that fifteen days previously he had been bitten upon this ear by a mosquito, that the puncture had aused excessive irritation, and the above described condition had rapidly ensued. He also complained of almost complete anssthesia of the left half of the face above the level of the ingle of the mouth, and added that he had noticed this loss of sensation for about a year. The boy was stripped and thoroughly examined, but nothing further abnormal could be discovered. As I had a suspicion of leprosy, two of the nodules on the ear were compressed until they were anæmic and then pricked with a needle, and cover-glass preparations were made of the clear serum that exuded. These were louble-stained by Ehrlich's method, as recommended by him for staining the bacilli of tubercle. The preparation first examined showed under a quarter-inch object glass two Eemale acari scabiei, and under a one-twelfth homogeneous vil immersion lens numerous bacilli lepræ, some of which were apparently within one of the acari, although it is possible that they were above or beneath it. Many bacilli Sepra were also to be seen about the legs and body of the acari and in other parts of the field. Carge numbers of similar bacilli were present in the other preparations and in preparations of the sanious discharge from the alcerated portion of the ear, some lying free, some in cells about the nuclei, and some in small masses resembling little balls. No bacilli were to be found in blood from the diseased ear nor in serum from the anæsthetic patch, and although careful search was made no more acari could be discovered. The Jacilli seen were very like the bacillus tuberculosis, but somewhat smaller, straighter and less rounded at the ends. The family history of the boy was bad: his mother suffered from advanced pulmonary tuberculosis, and her father, uncle and grandfather died of lung mischief; her brother also, but a few months ago, had severe hæmoptysis. The father of the lad denied having had syphilis. None of the members of the family have ever been known to be leprous. The boy himself, however, had been in the habit of playing about an old leper's house, although he denies ever having entered the house or having had any contact whatever with the man. I saw the patient again on Jan. 13th, 1893. The anæsthesia was more marked and the lobe of the ear was thicker, but the ulceration was tending to heal. Some slight thickening of the second toe of the right footwhich had lost its nail-was noticed. There has been no itching since the removal of the acari. Mercurial ointment to the ear has as yet been the only treatment. Crowds of bacilli were again found in the discharge from the ulcer and in serum from the nodules.

Singapore, Straits Settlements.

\section{A attirtor}

\section{HOSPITAL PRACTICE, BRITISH AND FOREIGN.}

Nulla autem est alia pro certo noscendi via, nisi quamplurimas et morDorum et dissectionum historias, tum aliorum tum proprias collectas habere, et inter se comparare.-MongaGNI De Sed. et Caus. Morb.,
lib. iv. Procmium.

\section{ST. BARTHOLOMEW'S HOSPITAL.}

TWO CASES OF LAPAROTOMY, ONE FOR RUPTURE OF THE FEMALF BLADDER AND THE OTHER FOR ACUTE LOCALISED INFLAMMATION OF THE ASCENDING COLON.

(Under the care of Mr. HowARD MARSH.)

IN commenting on this case Mr. Marsh remarks that, as rupture of the urinary bladder has as vet been treated in comparatively few instances by laparotomy and suture, it seems desirable that for the present every example should be recorded. Each must afford useful information in regard either to the course which these cases take or the different steps of the operation itself. In the present case the operation was performed eighty hours after the rupture had occurred. This is probably the longest period that has elapsed in any instance between the accident and the operation. It is needless to say that such an interval must in itself render success almost hopeless. In the majority of cases the period has been under thirty hours. In Mr. Heath's case, however, it was forty-two hours and a half and in Mr. McGill's sixty-six hours. Both patients died. In the present instance the abdominal cavity had become distended with urine mixed with blood-stained serum. This composite fluid had, however, apparently undergone but little putrefactive change ; it was not ammoniacal and had no odour of decomposition. The intestinal coats were somewhat thickened and injected; but no lymph ofos was present, so that peritonitis, though it had been already developed, had not been intense, nor had it reached an advanced stage. It was, in fact, a matter of surprise to notice how comparatively little the peritoneum had suffered from its long immersion in urine, and also how slight a degree of decomposition the urine had undergone. It seemed doubtful at the time whether it might not be wise to introduce a glass drainage-tube into Douglas's pouch. It was determined not to do so, as the peritoneum had been thoroughly irrigated and sponged dry.

CASE 1. Rupture of the female urinary bladder; laparotomy eighty hours after the injury; fatal peritonitis.-A woman aged thirty-four while intoxicated was kicked in the abdomen and otherwise very roughly used on the evening of Aug. 2nd, 1892. It was difficult to obtain the facts, but no immediate symptoms seem to have been developel. On the 5th the patient applied to a surgeon and said that she had passed only a teacupful of urine since the injury. A catheter was passed and only two ounces of blood-stained urine were withdrawn. On her admission immediately afterwards she looked ill and distressed and presented several bruises about the abdomen and other parts 